tolerably wide at $F$ and $G$, and which gradually diminishes in width towards $\mathrm{H}$, and finally becomes linear at M. Now as the effect of atmospheric absorption on the spectrum increases as you pass from $G$ toward $H$ and above $\mathrm{H}$, by diminishing the width of the spectrum you can in some measure neutralise the effect, and at one exposule obtain a photograph of nearly uniform intensity from end to end, though it is of variable width. If it were not for this it would be necessary to have the spectrum over-exposed at $\mathrm{G}$ in order to be visible above $\mathrm{H}$, or else to resort to an elaborate diaphraghming which is difficult.

It is my intention next season to return to the use of the 28 -inch reflector, because it collects nearly five times as much light as the 12 -inch does, after making allowance for the secondary mirror. Of course in a large reflector the difficulties of flexure and instability of the optical axis are much increased, and keeping a star on the slit will be troublesome, especially as the magnifying power on the image is about 50 .

As to the results obtained, it has already been mentioned that the spectra of several stars and planets have been photographed. The subject of planetary spectra will be reserved for a future communication. A preliminary examination at once shows that these stellar spectra are divisible into two groups: (I) those closely resembling the solar spectrum, and (2) those in which there are relatively but few lines, and those of great breadth and intensity. The photographs of the spectra of Arcturus and Capella are so similar to the solar spectrum, that I have not up to the present detected any material differences. But, on the other hand, the spectra of Vega and $a$ Aquilæ are totally different, and it is not easy without prolonged study and the assistance of laboratory experiments to interpret the results, and even then it will be necessary to speak with diffidence. I have not as yet obtained any stellar spectrum photographs belonging to the third and fourth groups of stellar spectra as described by Secchi. These, if obtainable, will aid materially in discussing the whole subject, but unless a star passes near the zenith it is hard to make a fair study of its spectrum by photography, because atmospheric absorption in the ultra-violet region increases rapidly as the altitude decreases. In the case of the sun I have found that at sunset the exposure necessary to photograph the spectrum above $\mathrm{H}$, is often 200 times as long as at mid-day.

In the case of the spectrum of Vega, when examined by the eye, the lines $C, F$, near $G$ and $h$, are readily visible, but lines such as $\mathrm{D}$ and $b$ are relatively faint. It is clear, then, that hydrogen exists to a large extent in the atmosphere of that star. But on examining the photograph of its spectrum it is evident that other lines just as conspicuous as the hydrogen lines, are present. One of these corresponds in position and character to $\mathrm{H}_{1}$, and seems to coincide with a calcium line. It appears to me, however, that the evidence of this coincidence is not complete.

In attempting to reason from these photographs as the matter now stands, it is necessary to try at every step farther experiments in order to find out whether the facts agree with the hypothesis, and it is this very condition of affairs that gives hopes of results valuable in their bearing on terrestrial chemistry and physics. In the photographs of the spectrum of Vega there are eleven lines, only two of which are certainly accounted for, two more may be calcium, the remaining seven, though bearing a most suspicious resemblance to the hydrogen lines in their general characters, are as yet not identified. It would be worth while to subject hydrogen to a more intense incandescence than any yet attained, to see whether in photographs of its spectrum under those circumstances any trace of these lines, which extend to wave-length 3700 , could be found.

It is to be hoped that before long we may be able to investigate photographically the spectra of the gaseous nebulæ, for in them the most elementary condition of matter and the simplest spectra are doubtless found.

\section{THE FUNCTION OF CHLOROPHYLL}

THE Report of the Berlin Academy for July last contains a remarkable paper by Prof. Pringsheim on this subject. In pursuing his researches upon chlorophyll, he had found that positive results could only be obtained by employing intense light, and in this paper he gives some account of the conclusions at which he has been enabled to arrive by the use of this method.

By means of a heliostat and a strong lens, the object to be observed under the microscope is brightly and constantly illuminated ; the effects of this illumination, which are striking, are produced in a few (3-6) minutes. Assuming that the object contains chlorophyll-corpuscles, the first visible effect is the rapid disappearance of the green colour, so that the object appears as if it had been lying for some days in alcohol, the corpuscles retaining however their form and consistence. Changes now gradually become apparent in the protoplasmic cellcontents ; the circulation of the protoplasm, where it exists, is arrested; the bridles of protoplasm rupture, and the nucleus is displaced; the ectoplasm contracts, becomes permeable to colouring-matters, and the turgidity of the cell disappears; the cell presents, in fact, all the symptoms of death.

It seems natural to suggest that these effects may be due, to some extent at least, to the action of the high temperature to which the cell is exposed under these conditions. Prof. Pringsheim, anticipating this criticism, is careful to point out that they are produced by all the different parts of the visible spectrum. They are quite evident when the light has previously passed through a solution of iodine in carbon disulphide, but they are more distinct when the light has passed through an ammoniacal solution of cupric oxide; the light to which the object is exposed consisting, in the former case, of red rays, in the latter. of blue and violet. Moreover, if the solution of iodine be so concentrated that only the rays of a greater wave-length than $0.00061 \mathrm{~m} . \mathrm{m}$. can pass, these effects are not produced although about eighty per cent. of the heat is transmitted; on the other hand, if the ammoniacal solution of cupric oxide be so concentrated that the whole of the rays of low refrangibility to a wavelength of $0.0005 \mathrm{I} \mathrm{m} . \mathrm{m}$. are absorbed, the effects are rapidly and vividly produced, although the amount of heat which passes is comparatively small. From these facts he concludes that the phenomena in question are the results not of the action of heat, but of that of light.

This important point being settled, he proceeds to determine in what manner this action of the intense light is affected by the atmosphere in which the object exists. As the result of a variety of experiments he finds that these effects are only produced when the atmosphere contains oxygen.

These are very briefly the facts which Prof. Pringsheim has ascertained by this method; we will at once pass to the consideration of the conclusions which he draws from them. He concludes, in the first place, that the decomposition (oxidation) of chlorophyll in the living plant is a process of combustion which is infuenced and promoted by the action of light, and which stands in no relation to the decomposition of carbonic acid by the plant. Since the green colour of the chlorophyll-corpuscles which have become blanched is not subsequently restored, even though the cell continue to live, it appears that this oxidation of the chlorophyll is not a normal physiological occurrence, but that it is purely pathological. Prof. Pringsheim was unable to find any substance in the cells which might be regarded as the product of the oxidation of the chlorophyll, neither could he detect any increase 
of the fat or starch in the blanched cell, nor the formation of grape-sugar or dextrin: he therefore concludes that the products of the oxidation of the chlorophyll are given off in the gaseous form. In the second place he concludes that the changes produced in the protoplasmic cell-contents are the direct effects of the photochemical action of light. That they are not due to the presence of the products of the decomposed chlorophyll is shown by the fact that they may be observed equally well in cells which do not contain chlorophyll, such as the stinging hairs of the nettle, \&c. This being the case, he infers that they too are produced by a process of combustion. The final conclusion to which he comes is that chlorophyll exercises a protective influence over the protoplasmic cell-contents by absorbing the actinic rays of the spectrum, thus diminishing the combustion (respiration) going on in the cell; that it is in fact the regulator of the respiration.

In another series of experiments Prof. Pringsheim endeavours to determine what are the substances which become oxidised in the process of respiration. He finds in all chlorophyll-containing cells, a substance which can be best extracted by immersing the parts-leaves for instance-in dilute hydrochloric acid for several hours. This substance, to which he gives the name of hypochlorin or hypochromyl, is of an oily nature; it is probably a hydrocarbon which consists only of carbon and of hydrogen, or one which contains oxygen also in its molecule, but in smaller proportion than the carbohydrates; it is soluble in alcohol, ether, turpentine, and benzol, but insoluble in water and in solutions of neutral salts; it occurs in long, red-brown, crystalline needles which soon harden after extraction, into an imperfectly crystalline mass of resinous or waxy consistence. It is readily oxidisable, as is shown by the fact that it disappears from the cell on exposure to intense light in an atmosphere containing oxygen, even sooner than the chlorophyll. Prof. Pringsheim is of opinion that this substance is the first product of the assimilation of the chlorophyll-corpuscle, and that starch and oil are subsequently formed from it by oxidation.

Applying these views to the life of the cell under ordinary conditions, the changes going on in the cell when exposed in the air to sunlight would be somewhat as follows: the general protoplasm would undergo some amount of oxidation, but not so much as to materially diminish its quantity or affect its properties; in the chlorophyll-corpuscles, oxidation would be either entirely arrested in consequence of the absorption of the actinic rays by the green colouring-matter, or at least so much diminished that the synthesis of the elements of water and carbonic acid to form hypochlorin could take place.

Since this paper is stated to be a merely provisional account of these very interesting experiments, it is hardly fair to submit it to a detailed criticism : it will be better to wait until the publication of the more complete account which Prof. Pringsheim promises in an early number of his Jahrbiucher. All that will be attempted at present is to indicate some of the principal difficulties which beset the acceptance of these new views. For instance, exception may be taken to the view that chlorophyll, when exposed to intense light is oxidised into gaseous bodies. It is well known that an alcoholic solution of chlorophyll, when exposed to sunlight in the presence of air, becomes oxidised and assumes a pale yellow colour; it may be that this also takes place in the chlorophyll-corpuscles, the yellow colour being hardly distinguishable on account of the smallness of the quantity which is present. Again, it will doubtless have occurred to every reader of this paper that hypochlorin may be nothing more than the wax which has long been known to exist in considerable quantity in chlorophyll-corpuscles. But the main difficulty has reference to the protective functions which Prof. Pringsheim ascribes to chlorophyll.
Admitting that the changes described above as occurring in the protoplasmic cell-contents are really the results of excessive oxidation consequent upon exposure to the intense light, it is evident that they are effected less quickly than the oxidation of the chlorophyll itself; that is to say that, ceteris paribus, the chlorophyll is more readily oxidised than the protoplasm. This being the case, it is not easy to understand how the former can efficiently protect the latter from the oxidising influence of light and regulate its respiration. This difficulty might perhaps be met by the suggestion that fresh supplies of chlorophyll are continually being formed, but we have no knowledge yet at present of any such continual formation of chlorophyll; on the contrary, it is a well-established fact that when once the chlorophyll of a corpuscle is oxidised, it does not regain its green colour.

It might perhaps be possible to obtain some further knowledge on this subject by observing the effects produced in cells by the action of strong light falling upon them, in some cases, directly, in others, after having passed through a solution of chlorophyll which would be renewed from time to time if necessary. If it were found, that, in the latter case, the cells remained uninjured whereas in the former they soon died, some important evidence in favour of Prof. Pringsheim's views would be obtained. It might then be possible to extend these experiments and to bring about the formation of starch from carbonic acid and water in the cells of fungi, and even of animals, for Mr. Geddes' interesting observations on planarians show that animal as well as vegetable protoplasm is capable of effecting this synthesis.

SYDNEY H. VINES

\section{THE CAMBRIDGE NATURAL SCIENCES}

WOULD science suffer by the division of the second part of the tripos into a non-biological and a biological division which might be taken in successive weeks with separate examiners?

Let us make sure that in future geologists know well their chemistry and physics, and insist on all biologists knowing how to work their microscope well. Perhaps some geologists will shrink from a division of subjects.; and consider that every geologist should know palæontology well. But the study of fossil plants and animals is surely a part of systematic botany and zoology; in fact, geology and palæontology would gain by being separated, so far as the one is physical, stratigraphical, petrological, and mineralogical, or the other truly biological. The knowledge of fossils as characterising a "formation" is not a biological subject ; a man may recognise fossils well enough for geological purposes who knows little of zoology properly so called. Biology suffers greatly from the want of palæontologists as distinct from physical geologists and petrologists. How many men are there who would agree that biology ("the study of things living or that have lived") is very difficult to separate from physical and non-biological subjects for examinational purposes? Let us acknowledge that it is more necessary that, at the commencement of his scientific career, a man should be known and recognised as a well-educated biologist than as a vegetable anatomist, or a palæontologist, or an embryologist. Every man seeking biological honours may find sufficiently little chemistry and physics in the first part of the natural sciences tripos not to daunt him, if he is capable of research. Surely it is better to secure a man's general physico chemical knowledge if he is to be a geological surveyor of the first rank, and also train him in elementary biology, than to encourage too early specialisation.

My proposal is that in the second part of the natural sciences tripos four or more examiners should be specially chosen to set and approve the biological questions, and 